\title{
Способ предотвращения дефектов отверстий в печатных платах
}

\author{
С. Ванцов, К. Т. н. ${ }^{1}$
}

УДК 621.3.049.75:621.95.01 | ВАК 05.11.14

\begin{abstract}
Данная статья является обобщающей в серии статей [1-6], опубликованных в журнале в 2016-2018 годах. Представлен завершающий результат исследований, касающихся возможностей обеспечения отсутствия дефектов внутренней поверхности отверстий в печатных платах, возникающих в процессе их сверления.
\end{abstract}

Д ля современных изделий электроники, реализуемых на базе использования различного рода печатных плат, характерно постоянное увеличение плотности монтажа и повышение требований по надежности. Это приводит в многослойных платах ко все бо́льшей плотности межсоединений в трехмерных структурах. Трансверсальные межсоединения в этих структурах осуществляются с помощью металлизированных отверстий, и количество таких отверстий постоянно растет, а требования к их качеству повышаются.

Своеобразие этих отверстий в современных многослойных платах заключается в малых величинах диаметра и относительно большой протяженности отверстий по отношению к нему. Такие отверстия могут быть получены двумя способами: лазерной обработкой или сверлением. На последнее приходится 96-97\% всех отверстий диаметром до 0,5 мм. Связано это с тем, что следующий этап технологического процесса изготовления печатных плат - металлизация отверстий - предъявляет специальные требования по шероховатости поверхности внутри отверстия. Нарушение этих требований приводит к ухудшению качества металлизации и, как следствие, к снижению качества выпускаемых плат. Лазерная же обработка не позволяет выполнить требования по шероховатости в принципе, поскольку процесс осуществляется выжиганием материала, то есть нагреванием его до состояния плавления, что приводит к остекловыванию внутренней поверхности отверстия. А это означает, что шероховатость слишком мала, и медь, которой обычно осуществляют металлизацию, плохо ложится и слабо удерживается внутри отверстия.

Своеобразием отличается и материал диэлектрических оснований печатных плат. Если не касаться СВЧ-плат и плат на металлическом основании, то в подавляющем большинстве случаев материалом, в котором формируются отверстия, является стеклотекстолит различных модификаций. При этом различие в модификациях, как

МАИ (НИу), доцент, vancov@medpractika.ru. правило, заключается в различном расположении слоев стеклоткани и разной плотности ее плетения, а также некоторых отличиях в составе связующего, в качестве которого чаще всего выступает эпоксидная смола. Особенностью последней является то, что до определенной температуры она ведет себя, как твердый материал, и это позволяет обеспечивать требуемую шероховатость внутри отверстия. Однако при нагревании ее выше некоторой температуры, называемой температурой стеклования, она резко меняет свои механические свойства и переходит в пластическое состояние. Эта температура составляет 130-180 ㄷ. При этом происходит размазывание связующего по стенкам отверстия, наволакивание смолы на спиральные канавки сверла и, в критических случаях, поднятие связующего при выходе сверла из отверстия с образованием буртика, что может привести как к отрыву медной фольги от композитного основания, так и к разрыву гарантированного пояска меди на контактной площадке [1].

Другой особенностью процесса сверления композитных материалов является то, что по ходу отверстия сверло проходит участки с существенно различной твердостью: твердость стекла, из которого изготовлена стеклоткань, составляет по Бринеллю примерно 500 НВ, что более чем на порядок выше твердости полностью полимеризованной эпоксидной смолы. При этом следует отметить, что участки с различной твердостью располагаются в композитном материале случайным образом [2].

Сверление отверстий в печатных платах осуществляется мелкоразмерными сверлами из твердых сплавов, таких как отечественные сплавы на основе карбида вольфрама ВК6 и ВK8. Поставщики таких сверл обычно назначают гарантированный ресурс сверла в количестве отверстий, которые можно просверлить новым сверлом без возникновения вышеописанных дефектов внутренней поверхности отверстия. Ресурс назначают исходя из допустимой степени износа режущих кромок сверла. Однако этот ресурс, с одной стороны, задается для определенного композитного материала и фиксированных режимов и параметров 
обработки, что может не совпадать с характеристиками процесса сверления на конкретном предприятии. С другой стороны, назначенный ресурс не учитывает случайного характера распределения твердости композитного материала. Поэтому реальный ресурс сверла в целом остается неизвестным, что при сверлении плат с несколькими тысячами отверстий может привести К возникновению дефектов поверхности отверстия.

Определить случаи возникновения дефектов визуальными или другими неразрушающими методами не представляется возможным в силу малости размеров отверстия. Единственным методом оценки состояния поверхности является изготовление микрошлифов отверстий, что, естественно, приводит к потере контролируемой платы. Отсюда возникает потребность в создании способа, позволяющего с высокой достоверностью определять количество бездефектных сверлений с учетом как материала изготавливаемых МПП, так и возможных особенностей технологического процесса, характерных для данного предприятия [3]

Как было сказано выше, основной причиной возникновения дефектов является повышение температуры связующего выше некоторого критического значения. Источником тепла в процессе сверления является трение задней поверхности сверла о материал композитного основания. Сила трения напрямую связана с усилием подачи сверла, которое возрастает по мере износа режущих кромок. Таким образом, по мере увеличения износа, то есть с ростом числа отверстий, просверленных одним сверлом, возрастает температура в зоне резания [4].

Температура в зоне резания может служить критерием для остановки процесса сверления до того момента, когда становится возможным появление дефектов стенки отверстия [1]. Но прямое ее измерение существующими в настоящее время аппаратными методами, тем более в производственных условиях, представляется затруднительным. Это связано как с малыми размерами получаемых отверстий (диаметр 0,5-1 мм, протяженность-не более 10 мм), так и со скоротечностью процесса: в среднем его длительность составляет около 0,5 с, что исключает возможность использования для определения температуры термопар или тепловизоров, время запаздывания при измерении которыми существенно выше.

Нами была построена математическая модель изменения температуры вершины сверла, как наиболее нагретой его части, в процессе сверления [5].

Процесс сверления является циклическим: нагревание сверла чередуется с его охлаждением. Нагревание происходит во время обработки композитного материала, а остывание - во время перехода инструмента в следующую позицию сверления.

Для части цикла сверления одного отверстия, связанной с нагреванием, изменение температуры имеет вид

$$
\mathrm{T}_{\mathrm{i}}=\mathrm{CN}_{\mathrm{i}} \sqrt{a \tau_{\mathrm{H}}}+\mathrm{T}_{\mathrm{ocr}(i-1))^{\prime}}
$$

где С и $а$-постоянные для конкретного технологического процесса величины, описывающие характеристики композитного материала и режимы обработки; $T_{i}$ - температура вершины сверла после окончания процесса сверления; $\tau_{i}$ - время нагревания сверла, то есть время сверления одного отверстия; $\mathrm{T}_{\text {ост(i-1) }}$ - температура сверла, с которой начинается нагревание в ходе сверления i-го отверстия, то есть температура, оставшаяся после сверления (i-1)-го (предыдущего) отверстия".

Все входящие в выражение параметры, связанные схарактеристиками материала и режимами обработки, для конкретного технологического процесса можно считать постоянными, за исключением усилия по задней поверхности $\mathrm{N}$, непосредственно связанного с усилием подачи сверла (усилием давления на плату во время сверления) и потому так же возрастающим по мере увеличения количества просверленных отверстий. При этом возрастание усилия N происходит случайным образом в силу высказанных выше положений.

Для части цикла сверления, связанной с охлаждением вершины сверла при переходе в следующую позицию, изменение температуры, как показано в [4], имеет вид

$$
T_{\text {ост }(i-1)}=\frac{C}{\sqrt{\pi}} e^{-b \tau}\left(1+\frac{\tau_{\text {пер } i}}{2 \tau_{\text {н }}}\right)+T_{\text {c }},
$$

где $b$ - постоянная величина, зависящая от условий охлаждения; $\tau_{\text {пері }}$ - время перехода от предыдущего отверстия к последующему (зависит от топологии платы); $\mathrm{T}_{\mathrm{c}}$ - температура окружающей среды.

Разработанная математическая модель дает возможность предложить способ предотвращения дефектов внутренней поверхности отверстий в композитных основаниях печатных плат. Для ее использования необходимо производить непрерывное измерение усилия подачи; с этой целью было разработано специальное устройство на базе тензометрического стола [6].

существо метода заключается в том, что в каждом цикле сверления производится контроль усилия подачи инструмента. Измеренная конкретная величина усилия вводится в модель в качестве исходных данных для расчета по выражению (1) значения температуры вершины сверла по окончании процесса получения одного отверстия. Модель работает в режиме реального времени; рассчитанное значение сопоставляется с критической температурой для данного конкретного связующего в композитном материале, в качестве которой выступает температура стеклования материала. Если критическая

Выражение (1) получено путем преобразования формулы (1) из статьи [4] для упрощения изложения. 


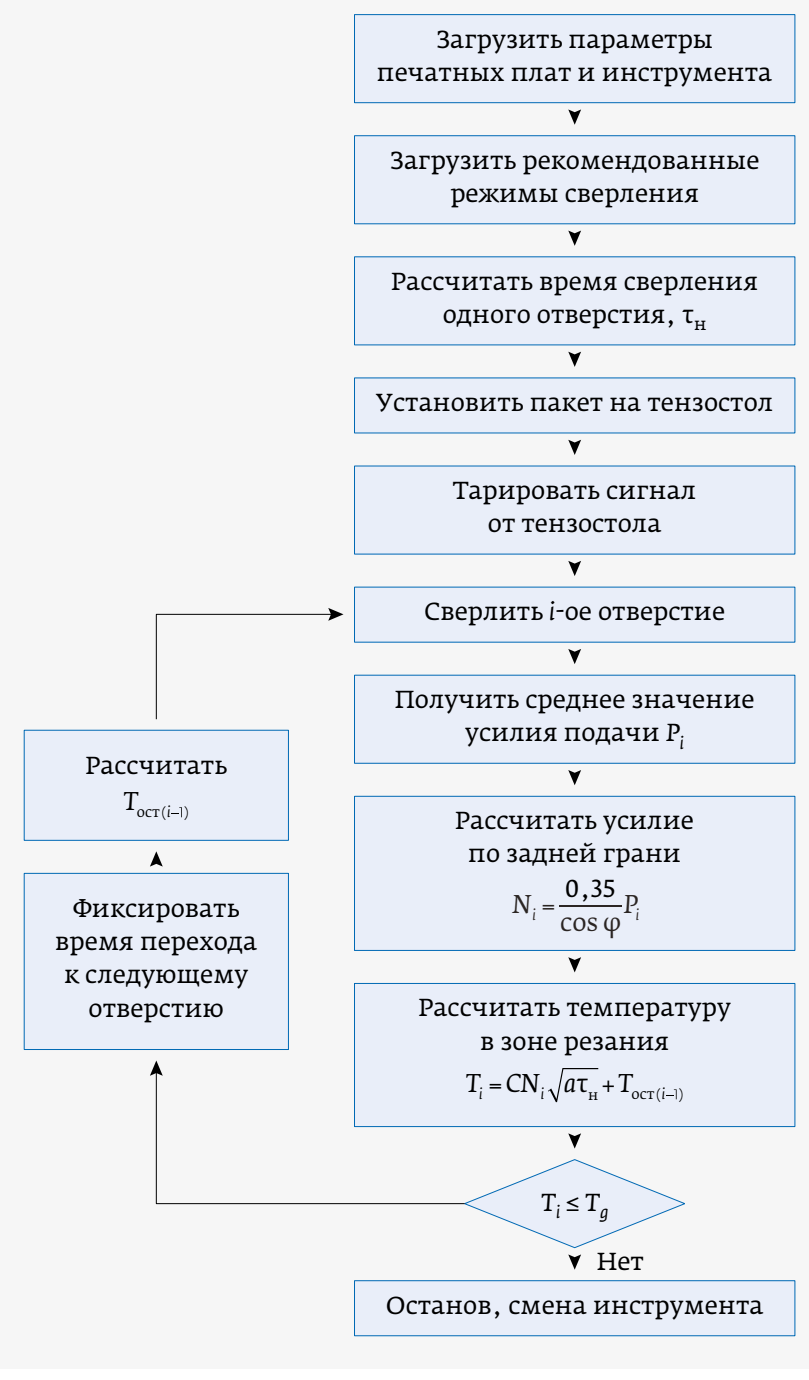

Рис. 1. Последовательность операций при реализации способа предотвращения дефектов внутренней поверхности отверстий в печатных платах на основе модели тепловых явлений в процессе сверления

температура не достигнута, то процесс получения отверстий может быть продолжен.

При расчетах учитывается и конкретная топология платы, то есть расположение контактных площадок, в которых требуется получить отверстие. Учет топологии осуществляется путем фиксации времени перехода от одного отверстия к другому и расчета на этой основе температуры остывания сверла по выражению (2). Моменты начала/окончания сверления определяются аппаратурой тензометрического стола по появлению/ снятию давления сверла на плату. Возможен и другой вариант: предварительный расчет длительности переходов на основе взятой из программы сверления информации о координатах отверстий и последовательности их сверления и данных о скорости перемещения шпинделя.

Превышение рассчитанной по выражению (1) температурой критического значения ведет к остановке процесса; для его продолжения необходимо заменить инструмент.

Алгоритм реализации предлагаемого способа представлен на рис. 1.

Эффективность способа была проверена в серии экспериментов. Результат одного из них приведен в табл. 1.

В ходе этого эксперимента было использовано 10 сверл диаметром 1,1 мм из сплава ВК8. Заявленный поставщиком ресурс для этих сверл составлял 2500 отверстий. В качестве диэлектрического основания использовался материал FR4. Из него была сформирована 8-слойная плата. Эксперимент осуществлялся на режимах, рекомендованных поставщиком сверл. Сверление проводилось по приведенному алгоритму.

Результат эксперимента позволяет сделать следующие выводы:

- в девяти из 10 реализаций процесс был остановлен правомочно. Появление дефекта в отверстии, на котором процесс был прерван, было подтверждено инструментальными методами;

- в реальности количество просверленных отверстий новым сверлом до появления дефекта может быть как больше, так и меньше заявленного поставщиком ресурса.

Обработка результатов всех серий экспериментальной проверки позволяет утверждать, что необходимость остановки процесса была подтверждена в 80\% случаев. В ходе проверки было также установлено, что, если для работы алгоритма будет назначена критическая температура на

Таблица 1. Результат эксперимента по проверке наличия дефектов стенок отверстий при останове по команде, формируемой математической моделью при достижении критического значения рассчитанной ею температурой в зоне резания

\begin{tabular}{lcccccccccc} 
Номер сверла & 1 & 2 & 3 & 4 & 5 & 6 & 7 & 8 & 9 & 10 \\
$\begin{array}{l}\text { Количество отверстий } \\
\text { до остановки процесса }\end{array}$ & 2744 & 2812 & 2608 & 2200 & 2268 & 2676 & 2404 & 2540 & 2336 & 2472 \\
\hline Дефект обнаружен & Да & Да & Да & Да & Да & Да & Да & Да & Нет \\
\hline
\end{tabular}


1-2 ${ }^{\circ} \mathrm{C}$ ниже температуры стеклования данного конкретного материала, то дефекты поверхности отверстий не будут возникать. Принятие этого результата в качестве рекомендации позволяет использовать предлагаемый способ в производстве печатных плат как эффективное средство исключения отказов процесса сверления по критерию качества получаемых отверстий.

\section{ЛИТЕРАТУРА}

1. Ванцов С., Медведев А., Маунг Маунг 3., Хомутская О. Надежность процесса сверления печатных плат, понятие отказа // Печатный монтаж. 2016. № 8. С. 168-172.

2. Ванцов С., Маунг Маунг 3., Войтковский С. Экспериментальное исследование усилия подачи при сверлении печатных плат // Печатный монтаж. 2017. № 8. С. 190-192.
3. Ванцов С., Маунг Маунг 3. Влияние температуры на надежность процесса сверления печатных плат // Печатный монтаж. 2017. № 2. С. 174-178.

4. Ванцов С., Маунг Маунг 3. Использование тепловой модели для определения параметров процесса сверления печатных плат // Печатный монтаж. 2017. № 6. С. 190192.

5. Ванцов С., Маунг Маунг 3. Квазидетерминированная модель тепловых явлений при получении отверстий в печатных платах // ЭлЕКТРОНИКА: Наука, Технология, Бизнес. 2018. № 1. С. 138-141.

6. Ванцов С., Медведев А., Маунг Маунг 3. Аппаратный способ предотвращения дефектов отверстий печатных плат // ЭЛЕКТРОНИКА: Наука, Технология, Бизнес. 2018. № 8. С. 142-145.

\section{КНИГИ ИЗДАТЕЛЬСТВА «ТЕХНОСФЕРА»}

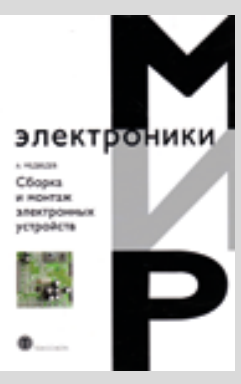

Цена 250 руб.

\section{СБОРКА И МОНТАЖ} ЭЛЕКТРОННЫХ УСТРОЙСТВ

\author{
Медведев A.
}

Производство электронной аппаратуры неуклонно наращивается, увеличивается плотность компоновки и миниатюризация аппаратуры, развиваются технологии поверхностного монтажа.

И несмотря на это в России отсутствуют свежие специализированные издания, посвященные современным проблемам сборки и монтажа. Сүществует лишь разрозненная информация в периодической печати и на сайтах фирм, поставляющих соответствующее оборудование. Но и эта информация не всем доступна.

Эта книга написана по материалам зарубежной периодической печати, международных конференций и, что особенно ценно, по результатам опыта работы таких высокотехнологичных предприятий отрасли, как LVS, Fastwel, МЭЛЗ, "Альтоника" и др.

Книга посвящена описанию процессов, материалов и оборудования, используемых в сборочно-монтажном производстве, и предназначена для начинающих специалистов в этой области технологий, преподавателей и студентов технических вузов по специальности «Конструирование и технология производства электронной аппаратуры». Надеемся, что опытным специалистам она поможет в обучении персонала. 